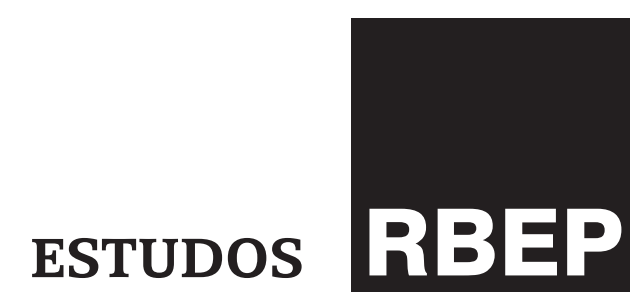

\title{
Contribuições das neurociências ao processo de alfabetização e letramento em uma prática do Projeto Alfabetizar com Sucesso*
}

Mário Medeiros

Edileuza de Lima Bezerra

http://dx.doi.org/10.1590/S2176-6681/316512801

\section{Resumo}

Destaca contribuições das neurociências à compreensão dos processos neurocerebrais envolvidos no ensino-aprendizagem e mostra como essas contribuições podem ser utilizadas em associação com a teoria de Aprendizagem Significativa de Ausubel (2002) e com a Psicogênese da Língua Escrita de Ferreiro e Teberosky (1979). Defende a necessidade de familiarizar os profissionais da educação com conhecimentos referentes a esses processos para conduzir à melhoria do desempenho acadêmico vigente na maioria de nossas escolas.

Palavras-chave: educação; neurociências; aprendizagem significativa.

* Parte deste trabalho foi apresentado como pesquisa em andamento no V Colóquio Internacional Educação e Contemporaneidade, promovido pela Universidade Federal de Sergipe (UFS), nos dias 21 a 23 de setembro de 2011 , na cidade de Aracaju-SE. 


\section{Abstract \\ Contributions from the Neuroscience to the beginning literacy process and literacy in a practice of the Project Alphabetization with Success}

The article highlights the contributions of Neuroscience to understand the neurological processes involved in the teaching and learning cycle and shows how these contributions can be used in association with the Theory of Meaningful Learning of Ausubel (2002) and Psychogenesis Language Writing of Teberosky and Ferreiro (1979). The paper advocates the need of education professionals to be acquainted with the knowledge regarding these processes, in order to promote the improvement of the current academic performance in most schools.

Keywords: education; Neuroscience; meaningful learning.

\section{Introdução}

O mundo contemporâneo apresenta mudanças irreversíveis impulsionadas por influências de fenômenos hegemônicos como a globalização, o neoliberalismo e as tecnologias da informação e comunicação (TICs). Esses fenômenos configuram as grandes preocupações públicas nos campos econômico, político, social e cultural e orientam as principais decisões governamentais. Essas preocupações incluem uma revisão nas formas de pensar e de preparar os indivíduos para as relações interpessoais, para o mercado de trabalho e para a cidadania. Sendo a escola parte destacada dessa preparação, é necessário visualizar melhor os contornos desse processo para que ela desempenhe com efetividade sua função social.

Pode-se começar com a hipótese de que talvez os modelos pedagógicos de décadas passadas fossem suficientes para aquela época porque havia menos exigência quanto ao que era solicitado ao indivíduo para atender às demandas do mundo social, do trabalho e da cidadania. Entretanto, com a crescente sofisticação das habilidades e competências exigidas para lidar com a reestruturação produtiva, com as ameaças ao ecossistema global e com a cidadania cosmopolizada, tornou-se mister, entre outras, a superação da especialização disciplinar do conhecimento, a superação dos modelos estereotipados de visões do mundo, bem como o desenvolvimento de arcabouços institucionais respeitadores das individualidades nascentes.

Os sujeitos contemporâneos, quase obrigados que são a participar de um verdadeiro frenesi informativo e semiótico, precisam ser competentes para refazerem, a seu modo, as complexas operações mentais que levam da interpretação de representações à produção de significados e sentidos, e destes à produção de outras representações. Sendo assim, as práticas pedagógicas tradicionais, baseadas em técnicas de memorização para repetição, e a correspondente formação de professores, até então 
consideradas adequadas, já não se mostram suficientes para a construção das habilidades e competências esperadas dos egressos dos sistemas escolares num mundo de progressiva aceleração do avanço tecnológico.

Essa realidade exige como condição para a mudança não apenas a solução de problemas estruturais das escolas e a agregação de novas disciplinas ao currículo, mas também conhecimento de como se aprende e sobre o que acontece quando aprendemos, subsídio que pode ser fornecido pelas neurociências. Portanto, não é exagerado dizer que parte do baixo desempenho apresentado por nossos alunos está relacionada a processos neurocognitivos que os profissionais da educação desconhecem ou acreditam ser pouco relevantes.

Neste artigo, relatamos uma experiência de utilização de contribuições das neurociências, da teoria de Aprendizagem Significativa, de Ausubel (2002), e da Psicogênese da Língua Escrita, de Ferreiro e Teberosky (1979), para tornar o processo de ensino-aprendizagem mais eficaz. Primeiramente, defendemos mudanças de foco nas formas de pensar e de preparar os indivíduos e, consequentemente, nos modelos pedagógicos que têm se mostrado insuficientes para atender à demanda social contemporânea de conhecimentos. No segundo momento, colocamos em destaque descobertas e contribuições resultantes de pesquisas das neurociências para melhorar a intervenção pedagógica e o desenvolvimento de uma aprendizagem significativa. Em seguida, assinalamos desafios a serem enfrentados pelos profissionais da educação na caminhada rumo a um ensino-aprendizagem de melhor qualidade. Por fim, apresentamos uma pesquisa-ação realizada com alunos do primeiro ano do primeiro ciclo da educação básica.

\section{Pressupostos teóricos}

\subsection{Memória e aprendizagem}

Falar de memória no processo de ensino-aprendizagem provoca, muitas vezes, confusões e equívocos quanto à sua utilização. Memorizar foi considerado por muito tempo sinônimo de decorar datas, textos, nomes e fórmulas. "Afinal, eram esses os conhecimentos exigidos nas provas, nas chamadas e nos testes escolares. Com base em estudos sobre o processo de aprendizagem da criança, concluiu-se que a decoreba era inimiga da educação" (Gentile, 2003, p. 43), e esse processo complexo e fascinante do cérebro que registra, armazena e evoca cada pensamento que elaboramos, cada lembrança, cada palavra que falamos e compreendemos, cada ação que executamos, o sentido que temos de nós mesmos e a nossa relação com os outros foi confundido com repetição e deixado de lado. Entendemos que isso foi um grande erro. Segundo Squire e Kandel (2003, p. 14), a memória é "o processo pelo qual aquilo que é aprendido persiste ao longo do tempo", sendo considerada, por diversos estudiosos, das mais diferentes áreas, a base do conhecimento e o caminho para a eficácia no ensino, se for adequadamente estimulada e utilizada. 
Os estudos contemporâneos comprovam a existência de tipos específicos de memória, que se classificam de acordo com a natureza dos elementos memorizados e segundo os processos neuropsicológicos envolvidos. Embora a terminologia para designar os distintos tipos de memória seja diversificada, eles se estruturam basicamente de acordo com a duração e o conteúdo do conhecimento a ser armazenado.

Pode-se dizer que os tipos de memória que mais interessam à educação são dois: memória de curto prazo, que "se refere à capacidade de reter a informação por um período curto de tempo, desde alguns poucos minutos até meia ou uma hora" (Dalgalarrondo, 2008, p. 93) e a de longo prazo, que evoca informações e acontecimentos ocorridos no passado, sendo um tipo de memória de capacidade e duração ampla, pois parece envolver mudanças na estrutura dos neurônios (Dalgalarrondo, 2008). A primeira deve ser conhecida e utilizada como ponto de partida para o caminho da verdadeira aprendizagem, que só se consolida com a memorização de longo prazo. Esta, para acontecer, necessita de aprendizagem significativa.

\subsection{Aprendizagem significativa e aprendizagem mecânica}

Ausubel (2002) destaca dois tipos de aprendizagem, tendo como base o conhecimento prévio do indivíduo: a aprendizagem mecânica e a aprendizagem significativa. A aprendizagem significativa pressupõe que o indivíduo possui esquemas cognitivos ordenados hierarquicamente e que os novos conhecimentos são a eles integrados de acordo com a compatibilidade que apresentarem com os conteúdos presentes nos esquemas cognitivos prévios. Os conhecimentos que formam esses esquemas são chamados por Ausubel de "subsunçores", e funcionam como uma espécie de âncora, onde os novos conhecimentos se engatam, integrando-se mais facilmente àquilo que o indivíduo já conhece.

O conhecimento significativo é, por definição, o produto de um processo psicológico cognitivo ("saber") que envolve a interação entre novas ideias logicamente e culturalmente compatíveis ou compatibilizáveis com as ideias anteriores já ancoradas na estrutura cognitiva particular do aprendiz. É relevante saber que, nesse processo de produção do conhecimento significativo, a própria estrutura cognitiva do indivíduo também se modifica, ampliando-se, diversificando-se e intensificando seu potencial, tornando-se, assim, cada vez mais capaz de processar novas informações, ideias e dados e ancorar os resultados desse processamento num continuum aparentemente ilimitado.

Diferentemente disso, na aprendizagem mecânica o conhecimento é armazenado de maneira arbitrária, não se relacionando com qualquer informação prévia existente na estrutura cognitiva. Portanto, apesar de a priori constituir-se como "novidade" para o aprendiz ao ser mecanicamente assimilado, não integra a estrutura cognitiva existente, caindo facilmente no esquecimento. Para a integração desse conhecimento mecânico, o indivíduo despende muito esforço e tempo para assimilar conceitos que seriam mais facilmente compreendidos se encontrassem uma "âncora" ou subsunçor. 
Logo, compreende-se que os subsunçores se constituem como otimizadores dos processos de aquisição de conhecimentos e que uma aprendizagem duradoura só se configura como aprendizagem significativa.

\subsection{Os novos desafios}

Comecemos pela constatação de que o contexto internacional em que nos situamos é fortemente caracterizado por aspirações crescentes, incertezas não transitórias e acontecimentos desconcertantes. A formação de cidadãos capazes de opinar, decidir e agir de forma autônoma e com mais celeridade nesse contexto tornou-se um dos grandes desafios para sistemas educacionais do mundo inteiro.

É consenso entre os educadores que um ensino-aprendizagem de qualidade multiplica as chances de uma inserção social que supere a alienação crescente, uma das marcas fortes das sociedades tecnicistas contemporâneas. Um passo nessa direção pode ser dado se as metodologias de ensino ativarem conscientemente os esquemas mentais correlatos às aprendizagens curriculares específicas indispensáveis ao enfrentamento bem sucedido dos desafios do mundo globalizado. Então, o que fazer para acionar os esquemas mentais já existentes em nossos alunos e direcionálos para a aquisição dos saberes curriculares?

A década de 1990 - conhecida como a "década do cérebro" - trouxe avanços tecnológicos e ferramentas para estudar a estrutura cerebral e o seu funcionamento. As técnicas de neuroimagem possibilitaram um mapeamento do cérebro humano e trouxeram subsídios para um maior conhecimento dos mecanismos cognitivos. Esses novos conhecimentos aplicados ao campo da educação nos possibilitam saber que lidamos, predominantemente, com três estilos de aprendizes. São eles: 1) aprendizes visuais, que prestarão uma atenção particular às informações visuais, incluindo texto; 2) aprendizes auditivos, para quem as informações tornam-se mais assimiláveis pela discussão; e 3) aprendizes cinestésicos ou táteis, que aprendem melhor quando envolvem diretamente o corpo e podem precisar se "tornar" aquilo que estão aprendendo (Sprenger, 2008, p. 33).

Sabe-se, há muito tempo, que aprendemos mais facilmente aquilo que nos possibilita satisfazer alguma das nossas necessidades básicas. Embora não seja possível estabelecer de uma vez por todas quais são as necessidades básicas de qualquer ser humano, elas podem ser agrupadas, grosso modo, em algumas grandes categorias. Maslow (1998), por exemplo, destaca as seguintes, entre outras: necessidades fisiológicas, necessidades de segurança, a sensação de estar inserido e ser amado, necessidade de estima, necessidade de autorrealização.

Tais conhecimentos podem ser utilizados como recursos pelos profissionais da educação na elaboração de estratégias de ensino articuladoras dos esquemas mentais que compõem os processos de memorização ampliada. Esses esquemas envolvem a passagem da memória de curto prazo para a de longo prazo. 
O seu manejo apropriado proporciona a otimização do processo de ensino-aprendizagem, como mostram os trabalhos de Baddeley, Anderson e Eysenck (2011). Isso pode começar com um ensino que respeite os diferentes estilos de aprendizagem dos alunos e utilize adequadamente os novos conhecimentos sobre os distintos tipos de memória e a formação de redes neuronais. Por conseguinte, o profissional da educação precisa estar apto a promover atividades didático-pedagógicas adequadas à ativação das áreas do cérebro responsáveis por processos neurocerebrais complexos, como a imaginação, que é básica para a inovação; a motivação, que é responsável pela elevação do entusiasmo para agir; a emoção, que é fundamental para o processo de formação e consolidação de memórias; e a atenção, que é indispensável para a formação de redes neuronais implicadas na evocação de memórias que dão suporte ao raciocínio lógico.

\section{Opção metodológica}

Ancorados nos pressupostos anteriormente descritos, realizamos uma pesquisa-ação visando avaliar a eficácia de algumas sugestões estratégicas que deles se desprendem. A nossa intervenção foi orientada por uma etnometodologia complexa aqui entendida como "o estudo das atividades estruturantes que constroem os fatos sociais da educação" (Mehan, 1978 apud Coulon, 1995, p. 307).

Entre as estratégias que utilizamos, destacamos algumas sugeridas por Rowe (1973), Fogarty (1997) e Sprenger (2008). São elas: 1) evitar perguntas não reflexivas, ou seja, aquelas que contribuem para uma aprendizagem mecânica, para o armazenamento de conhecimentos sem reflexão ou sem relação com conhecimentos prévios presentes na estrutura cognitiva. Essas perguntas geralmente começam com palavras e expressões do tipo "quem", "o que", "quando"; 2) fazer perguntas reflexivas, pois são elas que conduzem a interações cognitivas complexas entre informações que estão sendo adquiridas e conhecimentos já existentes na estrutura cognitiva. Essas perguntas geralmente começam com palavras e expressões do tipo "por que", "como", "deve", "pode" ou "que"; 3) começar a aula sempre com uma história relacionada à temática que será abordada; 4) usar músicas adequadas ao tema; 5) relacionar a aprendizagem aos problemas do mundo real; 6) usar novidades instigadoras; 7) indagar os alunos sobre semelhanças e diferenças entre textos e histórias; 8) respeitar o tempo de enfoque ou tempo de concentração; 9) utilizar o tempo de espera, que se caracteriza como uma pausa dada pelo professor para que o aluno possa refletir e responder uma pergunta; e 10) utilizar incentivos verbais do tipo "o que mais", "fale mais" para manter os alunos pensando sobre uma ideia ou conceito. A utilização dessas estratégias objetivou, em última instância, ativar determinadas redes neurais ou esquemas mentais já existentes, envolver e manter o cérebro ocupado em operações cognitivas relacionadas com conhecimentos prévios que, por isso mesmo, aumentam as chances 
de tornar o processo de ensino e aprendizagem mais dinâmico, rápido e satisfatório.

\subsection{Intervenção e resultados}

Nosso trabalho foi realizado em uma escola do agreste do Estado de Pernambuco com alunos oriundos de classes populares que habitam sítios e bairros da periferia, com situação econômica precária e pertencentes a famílias, cujos níveis de escolarização, na maioria das vezes, são inferiores ao ensino fundamental completo. Alunos com esse perfil ingressam na escola com o domínio de estratégias cognitivas próprias, desenvolvidas com base em recursos e referências do meio em que vivem e com leitura de mundo que possibilita, mesmo sem o domínio do Sistema de Escrita Alfabética (SEA) e de leitura, interpretar e contextualizar informações de modo adequado à solução de problemas do seu cotidiano.

O trabalho foi dividido em três etapas: a primeira foi constituída pela escolha da sala de aula objeto de estudo e entrevista com o professor regente da turma; a segunda pela observação de três dias alternados de aulas, que resultou num total de 12 horas, e pelo diagnóstico dos níveis silábicos sugeridos pela Teoria da Psicogênese da Língua Escrita de Ferreiro e Teberosky (1979); a terceira pela regência, pelos pesquisadores, de um total de 8 horas em uma sala do primeiro ano do primeiro ciclo da educação básica de uma escola localizada na zona urbana do município de Cachoeirinha (PE). A turma era constituída por um total de 22 alunos.

Escolhemos a sala do primeiro ano do primeiro ciclo da educação básica porque nessa etapa de ensino ocorre um trabalho especificamente voltado para a alfabetização, portanto, no nosso entendimento, adequada à verificação de hipóteses e conceitos das neurociências associadas à teoria de Aprendizagem Significativa de Ausubel (2002) e seus colaboradores, e pela Psicogênese da Língua Escrita de Ferreiro e Teberosky (1979).

Escolhida a turma, realizamos uma entrevista do tipo semiestruturada com a professora regente, aqui denominada de "Alfa". As perguntas foram referentes à sua formação acadêmica, à sua prática pedagógica cotidiana e ao perfil da turma. A professora relatou que é graduada em Pedagogia pelo Programa Especial de Graduação em Pedagogia (Progrape) da Universidade de Pernambuco e fez questão de declarar que restavam apenas dois anos para sua aposentadoria, expressando sensação de alívio. Quando questionada sobre sua prática pedagógica cotidiana, declarou estar seguindo o "método construtivista" porque, esclareceu, "faz brincadeiras e conta histórias durante a aula por exigência do Projeto Alfabetizar com Sucesso do Instituto Ayrton Senna", do qual sua turma participava. Trata-se de um programa que se declara, segundo sua coordenadora no município,

[...] de gerenciamento da aprendizagem nos cinco primeiros anos do ensino fundamental e cujo objetivo é reduzir a repetência e a evasão escolar através de práticas gerenciais e avaliações sistemáticas, de 
maneira a atuar previamente para que as redes de ensino não "produzam"

o fracasso e consequentemente alunos com distorção idade/série.

Quanto ao perfil da turma, a professora citou como aspectos positivos a mesma faixa etária para todos, no caso, seis anos, sendo a maior parte dos alunos do sexo feminino, e a quantidade de alunos na sala, que nesse projeto não pode ultrapassar o número de 25. Como aspectos negativos, apontou a indisciplina, a falta de acompanhamento dos pais e a heterogeneidade de níveis de desenvolvimento na aprendizagem (definida por ela como "alunos adiantados e alunos atrasados na aprendizagem"), o que exige atividades diferenciadas.

\subsubsection{A observação}

Nas observações, detectamos que a professora seguiu parcialmente o roteiro exigido pelo Projeto Alfabetizar com Sucesso: 1) acolhida, em que o professor opta por músicas ou brincadeiras; 2 ) leitura deleite, que explora a temática da semana; 3) correção do "para casa", que acontece em uma ficha de acompanhamento mensal preenchida pelo próprio aluno, com diferentes cores, de acordo com a realização da atividade; 4) desenvolvimento da aula, caracterizado pela exploração do conteúdo e das atividades no livro didático ou no caderno; 5) revisão do dia, que acontece de forma oral; e 6) o "para casa".

Notou-se que esse trabalho foi desenvolvido sem muita motivação, reflexão e dinamismo pela professora e também pelos alunos, que ficaram dispersos por muito tempo e entrando e saindo da sala. A música de acolhida foi a mesma durante os três dias (alternados) de observação. Somente em um dos três dias a professora contou uma história (Fábrica de monstros, de Rosa Amanda Strausz), cinco minutos antes de a aula começar, que não teve nenhuma relação com a temática da semana a ser trabalhada em seguida, o que pode ter contribuído para o desvio de concentração de alguns alunos durante a exploração da temática.

De acordo com Caine e Caine (1994 apud Sprenger, 2008, p. 30), "o cérebro adora histórias, pois é uma maneira natural de organizar as informações". Entretanto, segundo Sprenger (2008, p. 30), "a contação de histórias precisa de algum modo ser relacionada com o tema em questão para que desenvolva conexões emocionais com o conteúdo e contribua para o processo de memorização de longo prazo", isto porque "a experiência do cotidiano e os estudos de laboratório revelam que os incidentes emocionalmente carregados são mais lembrados do que os eventos nãoemocionais" (Schacter, 2001, p. 163).

A correção das tarefas de casa, apesar de acontecerem individualmente, foram centradas principalmente em observações do tipo certo e errado, não acontecendo qualquer reflexão sobre os erros. Em algumas situações quando a tarefa estava errada, a professora ditava ou escrevia a forma certa para o aluno transcrever. Na correção da tarefa de casa de um dos alunos, aqui denominado de "A", que respondeu errado por 
não compreender a estrutura da tarefa (a qual não estava pedagogicamente compreensível para um aluno de seis anos), a professora, depois de afirmar com tom de voz alterado que isso ocorreu por falta de atenção dele, apagou as respostas e ela mesma respondeu pedindo ao aluno que fizesse igual até aprender. Depois de alguns minutos, esse aluno conseguiu concluir a atividade recebendo o visto de certo e a palavra "parabéns" escrita em seu caderno. No preenchimento da ficha de frequência, a professora fez esse trabalho pelos alunos, afirmando que muitos marcavam errado e rasuravam a ficha, permitindo que apenas alguns alunos (aqueles que sabiam) fizessem o preenchimento. Com essa atitude, a professora não permitiu o contato dos "alunos que não sabiam" com esse gênero textual e o desenvolvimento de níveis de letramento direcionados à compreensão da estrutura e função social daquele gênero.

Agindo assim, a professora desperdiçou uma oportunidade para o desenvolvimento da reflexão, que é definida por Burrows (1995, p. 346) como uma "exploração e descoberta para extrair sentido de novas informações [...] reestruturando problemas e identificando as prováveis consequências" destes. Entretanto, para que a reflexão aconteça no processo de escolarização, são necessárias perguntas reflexivas por parte do professor. Essas perguntas, como dito anteriormente, são iniciadas com expressões como "o que", "o que mais" e "fale mais", seguidas pelos tempos de enfoque e de espera. O processo de reflexão é também o que permite a procura de referências associadas ao novo material na memória de longo prazo (Sprenger, 2008). Com os procedimentos que utilizou, a professora simplesmente estimulou nos alunos a memorização e a aprendizagem mecânica assinalada por Ausubel (2002), além de produzir uma sobrecarga da memória de curto prazo.

Na exploração da temática da semana, a professora utilizou questionamentos orais com contextualizações. Nesses momentos, os alunos se envolveram e participaram relatando fatos conhecidos ou vivenciados por eles e permaneceram bastante atentos. Isso aconteceu com a discussão da temática água, talvez porque em suas casas a falta desse recurso nas torneiras é fato constante e de conhecimento de todos. Esse momento foi muito proveitoso para os alunos, pois proporcionou uma interação significativa com conhecimentos prévios presentes na estrutura cognitiva desses sujeitos.

O proveito referido pode também ser explicado pela iminente sensação da satisfação de necessidades assinaladas por Maslow em sua teoria. Configura-se, ainda, como um processo característico da aprendizagem significativa destacada por Ausubel (2002) e da passagem da memória de curto prazo para a memória de longo prazo, realizada por meio da reorganização de redes cerebrais (Squire; Kandel, 2003). Esse último processo transforma a informação em representação duradoura capaz de ser evocada para novas conexões. Segundo Sprenger (2008, p. 164), "para a informação se transformar em memória de longo prazo, ela precisa de algum modo se tornar significativa". 
Nas aulas de Português, a professora utilizou o método analítico (das unidades maiores para as unidades menores), partindo de texto exposto em cartaz para leitura. Explorou-se prioritariamente as palavras-chave retiradas do texto e sua ortografia, inclusive na transcrição desses textos para o caderno. Em uma dessas aulas, a letra "m" e a palavra "mamãe" foram trabalhadas com enfoque diferenciado na repetição e na memorização do sinal gráfico til $(\sim)$, e não na relação entre a pauta sonora e as partes escritas, ou seja, da diferenciação sonora que o til $(\sim)$ provoca. Isso pode ter acontecido, talvez, porque a professora compreende o Sistema de Escrita Alfabética como a aquisição de uma técnica para o deciframento de um código e não como um sistema notacional (Morais; Albuquerque; Leal, 2005).

Nas aulas de Matemática, a exploração privilegiou a resolução de cálculos escritos envolvendo adição (que ela chamava "continha de mais"), subtração (que ela chamava "continha de menos") e as formas geométricas (que ela chamava simplesmente de "formas") com o uso de material concreto. Não houve uso de situações-problemas, o que pode resultar em sérios prejuízos para o processo de aprendizagem desses alunos. Destaque-se que estes estão na faixa etária de seis anos, momento em que a estrutura cognitiva não está adequadamente preparada para lidar com abstrações.

A capacidade de lidar com abstrações é desenvolvida e fortalecida com exercícios que impliquem identificação de consequências de fatos ou eventos antes que eles aconteçam. Isso explica a necessidade de se trabalhar com alguma referência do universo cultural concreto desses sujeitos (o que a professora fez), procedendo-se, no entanto, extrapolações para o nível abstrato (antecipação de consequências) que possam ser exemplificáveis por fatos corriqueiros da vida desses alunos ou por experimentos realizáveis por eles (o que a professora não fez). Uma possível consequência didática do procedimento utilizado pela professora pode ser o que Ausubel (2002) chama de aprendizagem mecânica e que nós habitualmente chamamos de decoreba, caracterizado por um conhecimento desancorado, fragmentado, e por isso, fácil de ser esquecido.

Em uma dessas aulas, foi trabalhado o conteúdo "formas geométricas" com a utilização de material concreto de madeira, em diferentes cores, espalhado no centro da sala para que os alunos pegassem individualmente a forma solicitada pela professora. Nesse processo, os demais alunos tentavam ajudar o colega que estava no centro, mas eram repreendidos pela professora, que afirmava que esse aluno deveria procurar sozinho, sem ajuda. Podemos perceber a vontade desses alunos de interagir durante a atividade, que explorou, principalmente, as cores e as formas correspondentes - azul e vermelho, quadrado, triângulo, retângulo e círculo-, mas sem nenhum levantamento do conhecimento prévio. A atitude da professora de impedir a interação nessa atividade foi desmotivante para aqueles que queriam participar não apenas pegando a forma solicitada por ela, mas também satisfazendo o desejo de ajudar o colega a satisfazer suas necessidades. Com procedimentos assim, bloqueia-se a satisfação da necessidade de estar inserido e ser estimado, no caso, ao mostrar o 
conhecimento na identificação de tais formas e utilizar esse conhecimento para ajudar outros. Nesse processo, a motivação é intrínseca, e:

[...] quando estamos intrinsecamente motivados, neurotransmissores como a dopamina são liberados em nosso cérebro [....] isso nos proporciona o estímulo necessário para a realização do objetivo. Esses mesmos neurotransmissores são liberados quando nosso objetivo é atingido. A dopamina, o prazer químico, faz-nos desejar conseguir de novo para repetir a boa sensação. (Sprenger, 2008, p. 25).

A revisão da aula não aconteceu em nenhum dia de observação. Verificamos que os alunos também esqueceram essa parte da rotina e não lembraram a professora. Para Sprenger (2008, p. 115), "a revisão é, na verdade, uma reconsideração da aprendizagem" e, por isso, é um momento crucial ao fortalecimento das conexões neurais existentes.

Essa etapa foi concluída com um diagnóstico dos níveis silábicos que aconteceu por meio de um ditado com um total de oito palavras, escolhidas em função de alguns critérios: 1) palavras que possibilitassem a compreensão no que se refere ao realismo nominal (por exemplo, boi e formiga); 2) palavras monossílabas, dissílabas, trissílabas e polissílabas para analisarmos como os alunos estavam grafando palavras com números de sílabas diferentes; 3) palavras com sílabas repetidas para analisarmos como os alunos, provavelmente silábico-qualitativos, estavam representando essas sílabas. Diagnosticamos cinco alunos pré-silábicos, três em transição do pré-silábico para o silábico-quantitativo, sete em transição do silábico-quantitativo para o silábico-qualitativo e cinco alunos no estágio silábico-qualitativo. Objetivamos, com esse diagnóstico, a obtenção de dados necessários à elaboração, no período da regência, de um planejamento contextualizado, com metodologia e atividades de reflexão que contemplassem as hipóteses quanto ao funcionamento do Sistema de Escrita Alfabética e de leitura diagnosticados e ainda proporcionassem avanços cada vez maiores dessas hipóteses.

Verificamos, ainda, que alguns alunos apresentaram mais interesse pelas figuras da história contada e pelo livro didático, que pediam de forma insistente para a professora mostrar. Outros demonstraram mais interesse pelo que a professora falava ou lia e outros ainda quando eram convidados à lousa e pelo material concreto. Isso nos levou a identificar três preferências de aprendizagem: 1) aprendizes visuais; 2) aprendizes auditivos; e 3) aprendizes cinestésicos ou táteis. Durante as aulas, essa diversidade parece não ter sido contemplada adequadamente, deixando necessidades insatisfeitas e resultando em consequências, de acordo com a teoria da hierarquia de Maslow (1998), o que pode ter comprometido a aprendizagem desses alunos.

\subsubsection{A regência}

Terminada a observação, iniciamos a etapa da regência. Fomos alertados a seguir a rotina e a metodologia exigida pelo Projeto Alfabetizar com Sucesso descrita anteriormente. Procuramos obedecer essa norma, 
mas de forma diferente daquela que observamos nas aulas da professora, visto que os alunos não foram atendidos em seus estilos de aprendizagem, em suas necessidades de aquisição do conhecimento, em seu tempo de enfoque e em seu tempo de espera. Buscamos "testar" algumas sugestões apontadas pelas neurociências e descritas anteriormente por Sprenger (2008). Nossa intenção foi a de analisar, comparar e interpretar os diferentes desempenhos dos alunos durante as etapas de observação e de regência dos pesquisadores.

Partimos do princípio que os sujeitos em processo de alfabetização já possuem conhecimentos sobre a língua (Ferreiro; Teberosky, 1979) e um nível considerável de letramento, sendo necessários desafios adequados para que esses sujeitos avancem cada vez mais em suas hipóteses.

Nessa etapa, objetivamos o desenvolvimento de relacionamentos, de ganchos emocionais com o conteúdo por meio do estabelecimento de relações da leitura deleite com a temática, da evocação e do enriquecimento do conhecimento prévio, contextualizações do conteúdo, uso de estímulos adequados a cada estilo de aprendizagem, atividades com reflexão anterior e posterior à sua realização, desenvolvimento de inferências, manipulação do concreto para conduzir ao abstrato, incentivo à descoberta a partir de estratégias pessoais e o uso de desafios que alargam a estrutura cognitiva cada vez que são solucionados.

Ancorados nas teorias mencionadas, recorremos a estratégias diferentes daquelas utilizadas pela professora. Optamos pelo uso de novidades atrativas que, ao serem percebidas pelo cérebro, liberam neurotransmissores excitadores, como a endorfina, que provoca a sensação de euforia e a liberação de energia física, e também colaboram para a aprendizagem e a memória (Sprenger, 2008).

Procuramos relacionar a alfabetização e o conhecimento matemático às experiências de vida e de linguagem dos educandos com o objetivo de favorecer o reconhecimento da relevância do conhecimento a ser ensinado e, por conseguinte, o desenvolvimento da motivação, que inclui dois componentes distintos: o gostar e o querer, que parecem envolver circuitos cerebrais diferentes, com a predominância da dopamina - o prazer químico como neurotransmissor (Moraes, 2009) e de emoções que organizam e coordenam a atividade cerebral em áreas do cérebro que formam memórias através da amígdala, estrutura emocional na área límbica que atua como moduladora devido a sua localização no cérebro (Sprenger, 2008) para, assim, aumentar as oportunidades de essas informações entrarem no processo de memória de longo prazo.

Para atender às hipóteses individuais quanto ao funcionamento do SEA diagnosticadas, utilizamos atividades no nível da palavra (composição e decomposição de palavras em sílabas e letras, composição de palavras quanto à presença de sílabas e letras iguais), atividades de análise fonológica (identificação e formação de rimas e aliterações) e de leitura concomitante à exploração das características e da função social de alguns gêneros textuais. 
O momento leitura deleite foi iniciado com leitura da letra do Hino Nacional Brasileiro, temática da semana, seguida de música acompanhada pelos alunos nos trechos conhecidos. Música adequada ao tema ensinado pode, em muitas pessoas, evocar vínculos emocionais (Sprenger, 2008). A correção da tarefa de casa foi feita de forma individual e coletiva com reflexão dos acertos e erros e convites à lousa. Questionamos os alunos com perguntas reflexivas sobre as estratégias utilizadas por eles na resolução das atividades. Esse momento foi importante porque os alunos perceberam diferentes formas de realizar aquelas atividades.

No preenchimento da sistemática de acompanhamento mensal, solicitamos a ajuda de dois alunos (aqueles com mais facilidade de desviar atenção) para auxiliar os colegas na identificação dos nomes, que estavam em ordem alfabética, chamados aleatoriamente pela letra e pela sílaba inicial. Aproveitamos essa situação de contato com o gênero textual ficha de frequência para explorar o som inicial dos nomes dos alunos, a ordem alfabética, a grafia das letras, a diferença entre letra e sílaba, a estrutura e a função social do gênero e para utilizar os nomes dos alunos como referência.

$\mathrm{Na}$ aula seguinte, trabalhamos a família silábica da letra "p", utilizando como referência o nome do aluno Pedro e o nome do brinquedo "pião", que se caracterizaram como palavras geradoras do poema explorado. Fomos conduzidos pela necessidade da situação a aprender a rodar o pião com os alunos, inicialmente com o aluno Pedro, que fez a primeira demonstração e, por conseguinte, na aula, pois o poema trabalhado abordava a brincadeira do pião. Os alunos foram convidados à lousa para escrever a letra "p", observando sua grafia. Levantamos e exploramos, inicialmente, os conhecimentos prévios por meio das características do aluno Pedro (nome completo, idade, cor do cabelo, da pele, onde morava, se possuía um pião como brinquedo) e do material concreto pião (qual a utilidade de um pião, quanto custa, onde é vendido, quem possui esse brinquedo, qual o nome da letra com que essa palavra se inicia, quais as outras palavras conhecidas com essa letra, quais os nomes de brinquedos, frutas, nomes de pessoas que eles conheciam com a letra "p", como essas palavras são escritas).

Procuramos, com essas atividades, satisfazer algumas das necessidades descritas por Maslow (1998) em sua teoria da hierarquia das necessidades. Procuramos oferecer estímulos aos aprendizes visuais, auditivos, cinestésicos ou táteis e procuramos facilitar a organização da aprendizagem de acordo com grupos, padrões e categorias. Fizemos assim porque "a maioria dos especialistas em memória sugere que a organização é a chave para uma boa memorização" (Sprenger, 2008, p. 62).

No geral, aprofundamos a reflexão sobre o SEA, a leitura e a oralidade por meio das socializações, das correspondências grafofônicas a partir da identificação da letra "p" em diferentes suportes textuais, buscando estimular aspectos motores, cognitivos e afetivos unidos ao contexto sociocultural do aluno.

Em Matemática, trabalhamos a ordem dos numerais e das letras por meio dos conceitos de antecessor e sucessor. Para facilitar a compreensão dos aprendizes cinestésicos ou táteis, convidamos alguns alunos para formar 
uma fila indiana e questionamos quem estava na frente e atrás do aluno " $\mathrm{A}$ ". Fazendo referência a esse exemplo, construímos o conceito de antecessor e sucessor dos numerais, que foi ainda mais explorado na resolução de situações-problema. Com isso, conduzimos os alunos à passagem do concreto para o abstrato, preparando-os para o aprimoramento do raciocínio lógico a partir de estratégias próprias, facilitando, ao mesmo tempo, a compreensão dos conceitos por meio da descoberta.

A revisão da aula aconteceu durante todo o processo de aprendizagem por meio de questionamentos orais que exigiam a organização do entendimento, resolução de situações-problema, contextualizações e identificação de semelhanças e diferenças. Esse processo possibilitou a manutenção da atenção, a reorganização das informações, a identificação e a correção de ideias e conceitos errôneos antes que fossem armazenados na memória de longo prazo.

\section{Conclusão}

Este trabalho partiu da hipótese de que os profissionais da educação necessitam conhecer as teorias das neurociências que descrevem os processos neuropsicológicos envolvidos na aprendizagem para que tenham subsídios para desenvolverem metodologias favorecedoras de ensino de qualidade e condizentes com o perfil de seus alunos.

Essa hipótese foi possível de ser testada e comprovada na pesquisaação, que mostrou, na etapa de observação, na sala de aula objeto de estudo, alunos dispersos, indisciplinados, desmotivados, pouco respeitados em suas preferências de aprendizagens, pouco atendidos em suas hipóteses quanto ao funcionamento do SEA, com necessidades de afeto e segurança, desenvolvendo aprendizagens mecânicas, desancoradas, fragmentadas e com pouca interação com o conhecimento prévio. Já na etapa da intervenção dos pesquisadores, esses mesmos alunos se tornaram mais motivados, participantes, seguros, reflexivos, envolvidos com a aprendizagem, estimulados em suas preferências de aprendizagens, atendidos e desafiados em suas hipóteses quanto ao funcionamento do SEA, desenvolvendo aprendizagens com interação significativa com o conhecimento prévio.

A primeira etapa foi desenvolvida pela professora regente da turma que, em sua atuação, demonstrou desconhecimento das teorias das neurociências e, portanto, não poderia utilizá-las para potencializar as situações de aprendizagens vivenciadas pelos alunos, ainda que não desconhecesse de todo as teorias de Aprendizagem Significativa de Ausubel (2002) e a Psicogênese da Língua Escrita de Emília Ferreiro e Ana Teberosky (1979).

A segunda etapa foi desenvolvida pelos pesquisadores, que procuraram relacionar a alfabetização às experiências de vida e de linguagem dos educandos por meio de um planejamento contextualizado com uma rotina de trabalho estruturada em atividades de reflexão sobre o SEA. Foram utilizadas estratégias apontadas pelas teorias das neurociências para 
potencializar situações desenvolvidas com base nas teorias da Psicogênese da Língua Escrita, de Emília Ferreiro e Ana Teberosky (1979), e da Aprendizagem Significativa, de Ausubel (2002).

Sabemos que pesquisas e discussões que envolvem as teorias das neurociências na educação não são comuns, e isso talvez explique a falta de conhecimento de alguns profissionais da educação. Talvez seja esse o motivo que levou a professora a expressar, ao término das atividades dos pesquisadores, o seguinte: "gostei bastante da metodologia utilizada e percebi que isso facilitou muito a aprendizagem dos alunos. O que vi e ouvi durante as aulas vai ajudar muito no meu trabalho", reconhecendo que essas teorias podem otimizar o ensino-aprendizagem e conduzir a melhorias na qualidade da educação. Dessa forma, os resultados deste trabalho apontam para a relevância da familiarização dos profissionais da educação com subsídios das neurociências para o processo de ensino-aprendizagem.

\section{Referências bibliográficas}

AUSUBEL, D. P. Aquisição e retenção de conhecimentos: uma perspectiva cognitiva. Lisboa: Paralelo, 2002.

BADDLEY, A.; ANDERSON, M. C.; EYSENCK. M. W. Memória. Porto Alegre: Artmed, 2011.

BURROWS, D. The nurse teacher's role in the promotion of reflective practice. Nurse Education Today, Philadelphia, v. 15, n. 5, p. 346-350, oct. 1995.

COULON, A. Etnometodologia e educação. In: FORQUIN, J. C. (Org.). Sociologia da educação: dez anos de pesquisas. Petrópolis: Vozes, 1995.

DALGALARRONDO, P. Psicopatologia e semiologia dos transtornos mentais. 2. ed. Porto Alegre: Artmed, 2008.

FERREIRO, E; TEBEROSKY A. A psicogênese da língua escrita. Porto Alegre: Artes Médicas, 1979.

FOGARTY, R. Brain compatible classrooms. Alington Heighs: Skylight, 1997.

GENTILE, P. Lembre-se: sem memória não há aprendizagem. Nova Escola, São Paulo, n. 163, p. 43-47, jun./jul. 2003.

MASLOW, Abraham H. Toward a psychology of being. New York: Wiley, 1998. 
MORAES, A. O livro do cérebro 2: sentidos e emoções. São Paulo:

Duetto, 2009.

MORAIS, A. G.; ALBUQUERQUE, E. B. C.; LEAL, T. F. (Org.).

Alfabetização: apropriação do sistema de escrita alfabética. Belo Horizonte: Autêntica, 2005.

ROWE, M. B. Teaching science as continuous inquiry. New York: MacGraw-Hill, 1973.

SCHACTER, D. The sevens sins of memory. New York: Hogton Mifflin, 2001.

SPRENGER, M. Memória: como ensinar para o aluno lembrar. Porto Alegre: Artmed, 2008.

SQUIRE, L. R; KANDEL, E. R. Memória: da mente às moléculas. Porto Alegre: Artmed, 2003.

Mário Medeiros da Silva, doutor em Ciências da Educação pela Universidade do Minho, Portugal, é professor adjunto do Departamento de Ciências Humanas e Educação da Universidade de Pernambuco (UPE), Garanhuns, Pernambuco, Brasil.

tramataia.a@gmail.com

Edileuza de Lima Bezerra é graduanda em Pedagogia pela Universidade de Pernambuco (UPE), Garanhuns, Pernambuco, Brasil.

leuzinha.l.bezerra@gmail.com

Recebido em 31 de outubro de 2013.

Solicitação de correções em 10 de novembro de 2014.

Aprovado em 20 de novembro de 2014. 